\title{
Kecanduan Smartphone Dengan Kepercayaan Diri Pada Remaja Usia 12-15 Tahun Tingkat Sekolah Menengah Pertama Di Kecamatan Kramat Jati, Jakarta Timur
}

\author{
Lily Noor Filaili, S.S., M.Si.M (0307057001), Hafna Rosyita B.CM., M.CM (0315077302), Peni \\ Rahmawati Handayani, S.Tr.Ftr \\ Universitas Binawan \\ Lilynoor@gmail.com
}

\begin{abstract}
Abstrak
Kecanduan smartphone berhubungan positif dengan kepercayaan diri remaja, hal ini dipengaruhi faktor materialisme yang ada pada remaja (Wang, et al., 2018). Ada penelitian yang menemukan hubungan tidak langsung antara screen time yang berlebih (smartphone over use) yang berubah menjadi kebiasaan menetap yaitu kecanduan smartphone dengan kepuasan pertemanan dan kepercayaan diri (self esteem) pada remaja perempuan. Perbedaan konsumsi jenis sosmed mempengaruhi level self esteem. Konsumsi sosmed bagi remaja dengan latar belakang sosioekonomi (SES) rendah lebih tinggi dibandingkan remaja berlatar belakang SES tinggi (Braig, et al; 2018).Penggunaan screen time yang berlebih seperti kecanduan smartphone karena mengakses media sosial berkaitan dengan kejadian pelecehan secara online, kurang tidur, kepercayaan diri rendah dan status BMI yang buruk pada remaja. Faktor-faktor resiko tersebut dapat meningkatkan remaja terkena gejala depresi (Kelly, Zilanawala, Booker, \& Sacker., 2018).Penelitian ini menggunakan desain cross sectional. Remaja melakukan pengisian kuesioner Smartphone Addiction Proness Scale (SAPS) dan Rosenberg Self Esteem Scale.
\end{abstract}

Kata Kunci : Smartphone, percaya diri, remaja

\begin{abstract}
Smartphone addiction is positively related to adolescent self-confidence, this is influenced by materialism factors that exist in adolescents (Wang, et al., 2018). There is a study that found an indirect relationship between excessive screen time (smartphone over use) which turned into a permanent habit, namely smartphone addiction with friendship satisfaction and self-esteem in adolescent girls. Differences in consumption of types of social media affect the level of selfesteem. Social media consumption for adolescents with low socioeconomic backgrounds (SES) is higher than adolescents with high SES backgrounds (Braig, et al; 2018). Excessive use of screen time such as smartphone addiction due to accessing social media is associated with incidents of online harassment, sleep deprivation, low self-confidence and poor BMI status in adolescents. These risk factors can increase adolescents' exposure to depressive symptoms (Kelly, Zilanawala, Booker, \& Sacker., 2018). This study used a cross sectional design. Adolescents filled out the Smartphone Addiction Proness Scale (SAPS) and Rosenberg Self Esteem Scale questionnaires.
\end{abstract}

Keywords: Smartphone, self-confidence, teenager

\section{Pendahuluan}

http://ejournal.urindo.ac.id/index.php/TI 
Total pengguna internet di Indonesia yang mengakses internet menggunakan mobile phone sebesar $85 \%$. Tersebar di daerah rural (pedesaan) maupun urban (perkotaan). Penetrasi pengguna smartphone mencapai angka mencapai 36,9\%. Sekitar 83,4\% pengguna internet di Indonesia berdomisili di wilayah perkotaan (Asosiasi Penyelenggara Jasa Internet Indonesia, 2015)4.

Remaja berada pada kelompok tertinggi dalam adiksi terhadap smartphone, menurut Wajcman, dkk (2007) yang dikutip oleh Cha dan Seo. Beberapa pengguna ponsel tersebut mengatakan bahwa mereka tidak dapat hidup tanpa ponsel, karena ponsel merupakan cerminan diri mereka (Cha \& Seo, 2018)2.

Menurut Wang dk, kecanduan smartphone berhubungan positif dengan kepercayaan diri remaja, hal ini dipengaruhi faktor materialisme yang ada pada remaja (Wang, et al., 2018)5.

Pada penelitian yang ditemukan hubungan tidak langsung antara screen time yang berlebih (smartphone over use) yang berubah menjadi kebiasaan menetap yaitu kecanduan smartphone dengan kepuasan pertemanan dan kepercayaan diri (self esteem) pada remaja perempuan. Remaja yang berinteraksi dengan screen time seperti kecanduan smartphone karena mengakses sosial media (sosmed) lebih sering memiliki self esteem yang rendah/buruk. Perbedaan konsumsi jenis sosmed mempengaruhi level self esteem. Konsumsi sosmed bagi remaja dengan latar belakang sosioekonomi (SES) rendah lebih tinggi dibandingkan remaja berlatar belakang SES tinggi (Braig, et al; 2018)6.
Pada temuan lainnya penggunaan screen time yang berlebih seperti kecanduan smartphone karena mengakses media sosial berkaitan dengan kejadian pelecehan secara online, kurang tidur, kepercayaan diri rendah dan status BMI yang buruk pada remaja. Faktorfaktor resiko tersebut dapat meningkatkan remaja terkena gejala depresi (Kelly, Zilanawala, Booker, \& Sacker., 2018)7.

Namun, ada penelitian yang menyatakan bahwa kecanduan smartphone dengan kepercayaan diri remaja cenderung tidak saling berkaitan, kecanduan smartphone lebih berefek kepada gejala kecemasan dan depresi pada remaja (Elhaia, Dvorakc, Levinea, \& Hall., 2017)8.

\section{Metode}

Penelitian ini menggunakan design cross sectional padaremaja usia 12-15 tahun di empat SMP di Kecamatan Kramatjati. Remaja mengisi kuesioner Smartphone Addiction Proness Scale dan Rosenberg Self Esteem Scale. Variabel penelitian dalam penelitian ini meliputi usia, jenis kelamin, karekteristik orang tua, kecanduan smartphone dan kepercayaan diri remaja.

Populasi target penelitian adalah remaja yang berusia 12-15 tahun dan pada tingkat 8 dan 9 di Kecamatan di Kecamatan Kramat Jati, Jakarta Timur, DKI Jakarta. Cara pengambilan sampel menggunakan teknik random sampling yang memenuhi kriteria inklusi sampai memenuhi jumlah responden yang diinginkan.

Sampel adalah populasi yang memenuhi kriteria inklusi, dimana jumlah sampel yang ditargetkan didapatkan dengan rumus di bawah ini:

$$
n=\left[\frac{Z \alpha+Z \beta}{0,5 \ln \left[\frac{(1+r)}{(1-r)}\right]}\right]^{2}+3
$$


Sumber: Ariawan, $1998^{30}$

$$
\begin{aligned}
& \text { Keterangan : } \\
& \mathrm{N}=\text { Jumlah sample } \\
& \mathrm{Z} \alpha=\text { Standar deviasi normal dengan tingkat kemaknaan } 1 \% \\
& \quad(\alpha=0,01) ; \text { maka } \mathrm{Z} \alpha=2,58 \\
& \mathrm{Z} \beta=\text { Standar deviasi normal dengan derajat kekuatan } 90 \% \\
& \quad(\beta=0,10) ; \text { maka } \mathrm{Z} \beta=1,28 \\
& \mathrm{r}=\text { korelasi minimal yang dianggap bermakna. } \\
& \mathrm{r}=0.25 \text { (Wang, 2017) })^{22}
\end{aligned}
$$

sumber : Ariawan. L, $1998^{23}$

$$
\begin{aligned}
& \mathrm{N}=\left[\frac{3.86}{0,5 \ln \left[\frac{1+0,25}{1-0,25}\right]}\right]^{2}+3 \\
& \mathrm{~N}=\left[\frac{3.86}{0,5 \ln \left[\frac{1,25}{0,75}\right]}\right]^{2}+3 \\
& \mathrm{~N}=\left[\frac{3.86}{(0,25511281188)}\right]^{2}+3 \\
& \mathrm{~N}=[15,112789259]^{2}+3 \\
& \mathrm{~N}=228,4+3 \\
& \mathrm{~N}=231,4 \text { dibulatkan menjadi } 232
\end{aligned}
$$

Sampel yang terlibat dalam penelitian ini berdasarkan hasil perhitungan sebanyak 232, akan tetapi peneliti mentargetkan sampel sebanyak 315 responden.

\section{Kriteria Inklusi}

a. Remaja yang berusia 12-15 tahun

b. Remaja SMP tingkat 2 dan 3 (kelas 8 dan 9) tahun ajaran 2018/2019.

c. Remaja yang memiliki media elektronik

\section{Kriteria Eklusi}

a. Remaja yang memiliki disabilitas (tuna netra, tuna rungu, tuna wicara, cacat fisik, dan retardasi mental)

b. Remaja SMP tingkat 1 (kelas 7).

Variabel penelitian ini adalah dengan menggunakan data primer, yaitu dengan melakukan wawancara dan observasi langsung pada remaja.

Pengumpulan data ini dilakukan pada remaja di 4 SMP. Setiap responden akan melakukan pengisian kuesioner dan melakukan aktivitas fisik. Pengisian kuesioner menggunakan Smartphone Addiction Proness Scale (SAPS) dan Rosenberg Self Esteem Scale. SAPS merupakan gambaran adiksi smartphone dengan empat subdomain yang diujikan yaitu gangguan fungsi adaptif, orientasi kehidupan virtual, penarikan dan toleransi. Sedangkan Rosenberg Self Esteem Scale merupakan pengukuran kepercayaan diri yang meliputi pernyataan tentang diri sendiri dan orang lain, baik yang positif maupun yang negatif. Waktu pengambilan data pada bulan April s.d Juni 2019.

Pengolahan data dilakukan dalam beberapa tahap, yaitu: editing, koding, dan entry data. Proses editing dilakukan untuk memeriksa kelengkapan data yang 
dikumpulkan, kemudian dilakukan koding dengan pemberian kode oleh peneliti untuk variabel yang telah dikumpulkan sesuai dengan kriterianya masing-masing. Selanjutnya data-data tersebut dimasukkan (entry) kedalam komputer untuk dilakukan proses analisis.

Analisis yang digunakan adalah meliputi analisis univariat, bivariat dan multivariat.

\section{Hasil}

\section{A. Analisis Univariat}

\section{Tabel 5.1}

Distribusi Frekuensi Karakteristik Responden

\begin{tabular}{lll}
\hline Variabel & n (Frekuensi) & $\%$ \\
\hline Jenis Kelamin & & \\
Laki - laki & 149 & 47,3 \\
Perempuan & 166 & 52,7 \\
Asal Sekolah & & \\
SMPN 150 & 102 & 32,4 \\
SMPN 20 & 68 & 21,6 \\
SMPN 50 & 101 & 32,1 \\
SMP Muhammadiyah IV & 44 & 14,0 \\
\hline
\end{tabular}

Berdasarkan tabel diatas terdapat 315 sampel. Dari 315 sampel yang tersebut sebanyak 149 orang (47,3\%)dengan jumlah sampel laki-laki, dan 166 orang (52,7\%) dengan jumlah sampel perempuan. Berdasarkan subjek penelitian siswa di
SMPN 150 sebanyak 102 orang $(32,4 \%)$, siswa SMPN 20 sebanyak 68 orang $(21,6 \%)$, siswa di SMPN 50 sebanyak 101 orang $(32,1 \%)$ dan siswa di SMP Muhammadiyah IV sebanyak 44 orang $(14,0 \%)$.

Tabel 5.2

Distribusi Frekuensi Kecanduan Smartphone Dan Kepercayaan Diri

\begin{tabular}{|c|c|c|}
\hline Variable & $\mathbf{N}$ & Persentase \\
\hline \multicolumn{3}{|c|}{ Kecanduan Smartphone $(n=315)$} \\
\hline Kecanduan rendah & 252 & 80 \\
\hline Kecanduan sedang & 46 & 14.6 \\
\hline Kecanduan tinggi & 17 & 5.4 \\
\hline $\begin{array}{l}\text { Kepercayaan } \\
(n=315)\end{array}$ & & \\
\hline Rendah & 284 & 90.2 \\
\hline Normal & 27 & 8.6 \\
\hline Tinggi & 4 & 1.3 \\
\hline
\end{tabular}

Berdasarkan tabel 5.2 Remaja yang mengalami kecanduan smartphone rendah sebanyak 252 siswa (80\%), kecanduan smartphone sedang sebanyak 46 siswa
(14.6\%) dan kecanduan smartphone tinggi sebanyak 17 siswa (5.4\%). Dan untuk kepercayaan diri, sebanyak 284 siswa (90.2\%) memiliki kepercayaan diri yang 
rendah, sebanyak 27 siswa $(8.6 \%)$ memiliki kepercayaan diri normal, dan siswa dengan harga diri sebanyak 4 siswa (1.3\%).

\section{B. Analisis Bivariat}

Pada penelitian ini analisis bivariat digunakan untuk mengetahui hubungan antara kecanduan smartphone dengan kepercayaan diri. Sebelum dilakukan analisis bivariat data yang dikumpulkan di uji kenormalitasannya. Hasilnya p-value $(0,0000)$ yang diartikan sebagai distribusi data tidak normal maka dari itu, dalam melakukan analisis bivariat menggunakan uji korelasi Spearman

Table5.3:Hubungan Kecanduan Smartphone Dan Kepercayaan Diri

\begin{tabular}{lll}
\hline & Kepercayaan Diri \\
\hline & $\mathrm{R}$ & $\mathrm{p}$ \\
Kecanduan Smartphone & 0.207 & 0.000 \\
\hline
\end{tabular}

\begin{tabular}{lllllll}
\hline Kecanduan & \multicolumn{9}{l}{ Kepercayaan Diri } \\
\cline { 2 - 7 } Smartphone & \multicolumn{2}{l}{ Rendah } & Normal & \multicolumn{2}{l}{ Tinggi } \\
& $\mathrm{N}$ & $\%$ & $\mathrm{~N}$ & $\%$ & $\mathrm{~N}$ & $\%$ \\
\hline Rendah & 227 & 90.1 & 22 & 8.7 & 3 & 1.2 \\
Sedang & 41 & 89.1 & 5 & 10.9 & 0 & 0 \\
Tinggi & 16 & 94.1 & 0 & 0 & 1 & 5.9 \\
\hline
\end{tabular}

Berdasarkan hasil tabel 5.4 hubungan kecanduan smartphone dan kepercayaan diri mempunyai hasil $\mathrm{r}=0,207$ yang berarti menunjukkan adanya hubungan searah dan lemah. Dimana secara statistik bermakna.

\section{PEMBAHASAN}

Responden penelitian berjumlah 315 orang. Karakteristik responden penelitian berdasarkan jenis kelamin

didominasi perempuan sebesar $52,7 \%$. Central Intelegence Agency World Factbook (2011) memperkirakan bahwa nilai harapan hidup wanita lebih besar dibanding dengan pria. Pada tahun 2009 angka harapan hidup dunia tercatat sebesar 66.57 tahun $(64,52$ tahun untuk laki-laki dan 68,76 untuk perempuan). 
Sedangkan indonesia, angka harapan hidup tercatat sebesar 70,76 tahun, pada laki-laki sebesar 68,26 tahun dan pada perempun sebesar 73,38 tahun

Dari hasil deskritif subjek penelitian yang dilakukan di SMP Kramat Jati Jakarta Timur tahun 2018, dari 315 responden didapatkan sebanyak 284 siswa (90,2\%) dengan kategori kepercayaan diri rendah, sebanyak 27 siswa $(8,6 \%)$ dengan kategori kepercayaan diri normal, dan 4 siswa $(1,3 \%)$ siswa dengan kategori kepercayaan diri tinggi.

Di wilayah Kecamatan Kramat Jati Jakarta Timur, Remaja Usia 12-15 tahun terbanyak mengalami kecanduan smartphone yang rendah dan memiliki kepercayaan diri yang rendah pula, adapun yang mengalami kecanduan smartphone tinggi dan memiliki kepercayaan diri tinggi namun jumlahnya lebih sedikit. Sedangkan hubungan kecanduan smartphone dengan kepercayaan diri adalah ada hubungan searah dan lemah serta secara statistik bermakna.

\section{Saran}

Dengan hasil yang ditunjukkan oleh penelitian ini maka peneliti menyarankan dilakukan penelitian lebih lanjut yang bersifat longitudinal maupun case control untuk melihat sebab akibat dari smartphone terhadap kepercayaan diri pada remaja. Pencegahan kecanduan smartphone pada remaja sebaiknya dengan meningkatkan kualitas dan kuantitas pertemanan serta pengawasan orangtua terhadap remaja pengguna smartphone. Orangtua dapat merubah pola asuh yang diterapkan menjadi pola asuh demokratis. Penerapan pola asuh ini dapat meningkatkan kualiatas hubungan orangtua dan remaja karena semakin sering melakukan interaksi dalam penyamaan persepsi berupa diskusi mengenai durasi penggunaan gadget, pemilihan jenis aplikasi yang di boleh di download disesuaikan dengan kebutuhan komunikasi dan penunjang kegiatan akademik sekolah. Begitupun dengan pola pendidikan yang diterapkan oleh pendidik atau guru agar dalam pengajarannya lebih variatif sehingga remaja tidak jenuh dan tertekan selama proses belajar mengajar, serta dari pihak sekolah agar dapat mengeksplorasi berbagai kegiatan di sekolah yang dapat meningkatkan interaksi sosial pada remaja sehingga waktu penggunaan gadget berkurang 


\section{Daftar Pustaka}

1. Kuss, D., \& Mark, M, D. (2017). Social Networking Sites and Addiction: Ten Lessons Learned. International Journal of Environmental Research and Public Health. 14(311). $1-17$.

2. Kuss, D.J., \& Griffiths, M.D. (2011). Online Social Networking and Addiction-A Review of the Psychological Literature. International Journal of Environmental Research and Public Health. 8. 3528-3552.

3. Asosiasi Penyelenggara Jasa Internet. (2017). Penetrasi \& perilaku pengguna internet Indonesia. Indonesia.

4. Curtis, A.C. (2015). Defining adolescence. Journal of Adolescent and Family Health. $7(2) .1-40$

5. Blackmore, S., J \& Mills, K., L. (2014). Is Adolescence a Sensitive Period for Sociocultural Processing?. Annual Review of Psychology. 15(46). 1-21.

6. Duell, N., Steinberg, L., Chein, J., Al-hassan, S.M., Bacchini, D., Lei, C. et al. (2016). Interaction of Reward Seeking and Self-Regulation in the Prediction of Risk Taking: A Cross-National Test of the Dual Systems Model. Developmental Psychology. 52(10). 1593-1605.

7. Crone, E.A., \& Konjin, E.A. (2018). Media use and brain development during Adolescence. nature communication. 9(588). 1-10.

8. Nutall, F.Q. (2015). Body Mass Index Obesity, BMI and Health : A Critical Review. Nutr Today. Vol 50(3) : 117-128.

9. Laurson, K. R., Lee, J. A., Gentile, D. A., Walsh, D. A., \& Eisenmann, J. C. 2014. Concurrent Associations between Physical Activity, Screen Time, and Sleep Duration with Childhood Obesity. ISRN Obesity Journal. Volume 2014, Article ID 204540, Hal 16. http://dx.doi.org/10.1155/2014/204540

10. Khajeheian, D., Colabi, A. M., Nordiana, Jasimah, C. W., \& Jenatabadi, H. S. (2018). Effect of Social Media on Child Obesity: Application of Structural Equation Modeling with the Taguchi Method. Int. J. Environ. Res. Public Health. Vol 15 (1343) : 1-22. doi:10.3390/ijerph15071343.

11. Kelly, Y., Zilanawala, A., Booker, C., \& Sacker, A. (2019). Social Media Use and Adolescent Mental Health: Findings From the UK Millennium Cohort Study. E Clinical Medicine. Vol 6 : 59-68. https://doi.org/10.1016/j.eclinm.2018.12.005.

12. Fardouly, J., Diedrichs, P.C., Vartanian, L. R., \& Halliwell, E. (2015). Social Comparisons on Social Media: The Impact of Facebook on Young Women's Body Image Concerns and Mood. Hal 1-38. http://eprints.uwe.ac.uk/24574/1/Fardouly\%2C\%20Diedrichs\%2C\%20Vartanian $\% 2 \mathrm{C} \% 2$ 0\%26\%20Halliwell\%20\%28in\%20press\%29.pdf.

13. Robinson, T. N., Banda, J. A., Hale, L., Lu, A. S., Fleming-Milici, F., Calvert, S. L., Wartella, E. 2019. Screen Media Exposure and Obesity in Children and Adolescents. PEDIATRICS Jounal. Volume 140, number s2. DOI: https://doi.org/10.1542/peds.2016$\underline{1758 \mathrm{~K}}$. 
14. De Vries, D. A., Peter, J., De Graaf, H., Nikken, P. (2016). Adolescents' Social Network Site Use, Peer Appearance-Related Feedback, and Body Dissatisfaction: Testing a Mediation Model. J Youth Adolescence. Vol 45 : 211-224. doi 10.1007/s10964-0150266-4.

15. Prabhu, S., \& D'Cunha, D. (2018). Comparison of Body Image Perception and The Actual BMI and Correlation with Self Esteem and Mental Health : A Cross Sectional Study Among Adolescents. International Journal of Health \& Allied Sciences. Vol 7:145 (9) : 15. DOI:10.4103/ijhas.IJHAS_65_16.

16. Burnette, B., Kwitowski, M. A., Mazzeo, S. E. 2017. -I don't need people to tell me I'm pretty on social media :I Aqualitative study of social media and body image in early adolescent girls. Elsivier Body Image Journal. Volume 23 : Hal 114-125. http://dx.doi.org/10.1016/j.bodyim.2017.09.001.

17. Ferguson, C. J., Muñoz, M. E., Garza, A., \& Galindo, M. (2013). Concurrent and Prospective Analyses of Peer, Television and Social Media Influences on Body Dissatisfaction, Eating Disorder Symptoms and Life Satisfaction in Adolescent Girls. $J$ Youth Adolescence. Hal 1-14. DOI 10.1007/s10964-012-9898-9.

18. Sawyer, S.M., Azzopardi, P.S., Wickremarathne, D. \& Patton, G.C. (2018). The age of adolescence. Lancet Child Adolesc Health. 1-6.

19. Arain, M., Haque, M., Johal, L., Mathur, P., Nel, W., Rais, A. et al. (2013). Maturation of the adolescent brain. Neuropsychiatric Disease and Treatment. 9. 449-461.

20. Asosiasi Penyelenggara Jasa Internet. (2017). Penetrasi \& perilaku pengguna internet Indonesia. Indonesia.

21. Sanders, R.A. (2013). Adolescent Psychosocial, Social, and Cognitive Development. Pediatrics in Review. 34(8). 1-6.

22. Kaplan, A.M. \& Haenlein, M. (2010). Users of the world, unite! The challenges and opportunities of Social Media. 53. 59-68.

23. Olufadi, Y. (2015). Social networking time use scale (SONTUS): A new instrument for measuring the time spent on the social networking sites. Telematics and Informatics Journal. Volume 33 Hal : 452-471.

24. Kolimechkov, S. (2016). Body Mass Index. STK Sport UK. Hal 1-7. doi: 10.13140/RG.2.2.31492.94086.

25. Maddison, R., Foley, L., Mhurchu, C.N., Yannan, J., Jull, A., Prapavessis, H., Hohepa, M., \& Rodgers, A. (2011). Effect of Active Video Games on Body Compotition : A Randomized Controlled Trial. Am J Clin Nutr. Vol 94 : 156-163. https://doi: 10.3945/ajcn.110.009142.

26. Raistenskis, J., Sidlauskiene, A., Strukcinskiene, B., Baysal, S.U., \& Buckus, R. (2016). Physical Activity, Physical Fitness in Obese, Overweight and Normal-Weight. Turkish Journal Medical Sciences. Vol 46 : 443-450. doi:10.3906/sag-1411-119.

27. Clemente, A.P., Santos, C.D., Silva, A.A., \& Sawaya, A.L. (2011). Rev Paul Pediatr. Vol 29(2) : 171-177.

28. Riset Kesehatan Dasar, Kementerian Kesehatan RI, 2013.

29. Fryar, C.D., Carroll, M.D., \& Ogden, C.L. (2016). Prevalence of Overweight and Obesity Among Children and Adolescents Aged 2-19 Years : United States, 1963-1965 Through 2013-2014. National Center For Health Statistics. 1-6.

30. Ariawan, I. (1998). Besar Dan Metode Sampel Dalam Penelitian Kesehatan. Universitas Indonesia. 